\title{
Stainless Steel Surface Nitriding in Open Atmosphere Cold Plasma: Improved Mechanical, Corrosion and Wear Resistance Properties
}

\author{
Alice O. Mateescu 1,*, Gheorghe Mateescu ${ }^{1}$, Adriana Balan 2,*, Catalin Ceaus ${ }^{2}$, Ioan Stamatin ${ }^{2}$, Daniel Cristea ${ }^{3} \mathbb{D}$, \\ Cornel Samoila $^{3,4, *}$ and Doru Ursutiu ${ }^{5,6}$ (D)
}

1 Horia Hulubei National Institute of Physics and Nuclear Engineering, 30 Reactorului Street, 077125 Magurele, Romania; mateescu@nipne.ro

23 Nano-SAE Research Centre, Faculty of Physics, University of Bucharest, 405 Atomistilor Street, 077125 Magurele, Romania; catalin@3nanosae.org (C.C.); istarom@3nanosae.org (I.S.)

3 Department of Material Science, Faculty of Materials Science and Engineering, Transilvania University of Brasov, 1 Colina Universitatii, 500036 Brasov, Romania; daniel.cristea@unitbv.ro

4 Technical Science Academy of Romania, 125 Calea Victoriei, 010071 Bucharest, Romania

5 Electronics and Computer Department, Faculty of Electrical Engineering and Computer Science, Transilvania University of Brasov, 29 Eroilor Blvd., 500036 Brasov, Romania; udoru@unitbv.ro

6 Romanian Academy of Scientists, 3 Ilfov Street, 050045 Bucharest, Romania

* Correspondence: amateescu@niham.nipne.ro (A.O.M.); andronie@3nanosae.org (A.B.); csam@unitbv.ro (C.S.)

check for updates

Citation: Mateescu, A.O.; Mateescu, G.; Balan, A.; Ceaus, C.; Stamatin, I.; Cristea, D.; Samoila, C.; Ursutiu, D. Stainless Steel Surface Nitriding in Open Atmosphere Cold Plasma: Improved Mechanical, Corrosion and Wear Resistance Properties. Materials 2021, 14, 4836. https://doi.org/ $10.3390 /$ ma14174836

Academic Editor: Rainer Hippler

Received: 6 July 2021

Accepted: 19 August 2021

Published: 26 August 2021

Publisher's Note: MDPI stays neutral with regard to jurisdictional claims in published maps and institutional affiliations.

Copyright: (c) 2021 by the authors. Licensee MDPI, Basel, Switzerland. This article is an open access article distributed under the terms and conditions of the Creative Commons Attribution (CC BY) license (https:// creativecommons.org/licenses/by/ $4.0 /)$.

\begin{abstract}
This work presents preliminary results regarding improving the mechanical, wear and protective properties (hardness, coefficient of friction, corrosion resistance) of AISI 304 stainless steel surfaces by open atmosphere cold plasma surface treatment method. Comparative evaluations of the morphological, corrosion resistance, mechanical and tribological properties for different periods of treatment (using $\mathrm{N}_{2}$ gas for cold plasma generation in an open atmosphere) were performed. AFM surface analyses have shown significant surface morphology modifications (average roughness, FWHM, surface skewness and kurtosis coefficient) of the treated samples. An improved corrosion resistance of the $\mathrm{N}_{2}$ treated surfaces in open atmosphere cold plasma could be observed using electrochemical corrosion tests. The mechanical tests have shown that the surface hardness (obtained by instrumented indentation) is higher for the 304 stainless steel samples than it is for the un-treated surface, and it decreases gradually for higher penetration depths. The kinetic coefficient of friction (obtained by ball-on-disk wear tests) is significantly lower for the treated samples and increases gradually to the value of the un-treated surface. The low friction regime length is dependent on the surface treatment period, with a longer cold plasma nitriding process leading to a significantly better wear behavior.
\end{abstract}

Keywords: surface nitriding; open atmosphere; cold plasma; corrosion resistance; hardness; wear

\section{Introduction}

Stainless steels are widely used in industrial applications due to their durability and high corrosion resistance. However, there are some weaknesses of steel (such as low hardness and poor wear resistance) that need to be addressed. A promising surface engineering technology is nitriding, as it enables the atomic nitrogen diffusion into the superficial surface layers of a material creating a surface with increased properties, e.g., increased hardness, wear and corrosion resistance. These processes are more commonly applied on low-carbon steels, but they are also used on medium-carbon or high-carbon steels that contain metals with $\Delta \mathrm{G} / \mathrm{mol}<0$ at $\mathrm{T}<100{ }^{\circ} \mathrm{C}$, according to the Ellingham diagram, as well as on titanium, zirconium, aluminum, molybdenum, etc. and their alloys [1]. 
Regarding the plasma nitriding of Fe alloys, the reactivity of the nitriding media is not due to the high temperature, as is the case for gas nitriding or salt bath nitriding processes, where the temperature grows up to $600{ }^{\circ} \mathrm{C}$, but to the nitrogen gas ionized state $\left(\mathrm{N}_{2}{ }^{+}\right)$, that interacts with the surface material. It causes the diffusion of the nitrogen ions inside of the material structure and the occurrence of chemical reaction with components of the Fe alloys [2-7]. It is well known that the reaction of nitrogen with the usual components of stainless steel (Fe, Ni, Cr, Mo, Ti, Mn, C, Si, etc.) spontaneously occurs at low temperatures, only if the standard Gibbs energies of the nitride formation in the low temperature range are negative values $(\Delta G<0)$ [8]. As one could see in the Ellingham diagrams for selected nitrides, the Gibbs free energy that predicts the direction of a chemical reaction concerning certain chemical compounds of $\mathrm{N}_{2}\left(\mathrm{ZrN}, \mathrm{TiN}, \mathrm{AlN}, \mathrm{Nb}_{2} \mathrm{~N}, \mathrm{Mg}_{3} \mathrm{~N}, \mathrm{Si}_{2} \mathrm{~N}_{4}, \mathrm{VN}, \mathrm{CrN}, \mathrm{Cr}_{2} \mathrm{~N}\right.$ and $\mathrm{Mo}_{2} \mathrm{~N}$ ) has negative values on a large range of temperatures (300-1200 K); these are the same temperatures that are used in the classical ion nitriding as well as in the atmospheric cold plasma ion nitriding [9].

The diffusion process and chemical reaction of nitrogen in a steel material (plain carbon steel, low-alloy steel, high-alloy steel) are accelerated using an increased temperature in all three types of nitriding processes (not only in ion nitriding) by producing different phases, resulting in different phases such as $\alpha, \gamma, \gamma^{\prime}, \varepsilon$ phases. The $\alpha+\varepsilon$ phases appear at low temperatures, specific for cold plasma treatment in open atmosphere. The $\alpha$ phase is a ferritic steel phase with a BCC (body centered cubic) crystalline structure, while the $\varepsilon$ phase is an intermetallic compound with an HCP (hexagonal close packed) crystalline structure [10]. The major components of the Fe-N binary phase diagram that could be formed in an iron nitriding process ( $\mathrm{FeN}, \mathrm{Fe}_{2} \mathrm{~N}, \mathrm{Fe}_{3} \mathrm{~N}, \mathrm{Fe}_{4} \mathrm{~N}, \mathrm{Fe}_{3} \mathrm{~N}_{4}, \mathrm{Fe}_{16} \mathrm{~N}_{2}$, etc.) exhibit different thermal stabilities as well as varying magnetic properties [11]. To expand, FeN and $\mathrm{Fe}_{2} \mathrm{~N}$ are $\mathrm{N}$-rich phases, while $\mathrm{Fe}_{3} \mathrm{~N}, \mathrm{Fe}_{4} \mathrm{~N}, \mathrm{Fe}_{3} \mathrm{~N}_{4}, \mathrm{Fe}_{16} \mathrm{~N}_{2}$ are N-poor phases; $\mathrm{Fe}_{4} \mathrm{~N}$ and $\mathrm{Fe}_{3} \mathrm{~N}$ are ferromagnetic phases; $\mathrm{Fe}_{3} \mathrm{~N}$ change into the paramagnetic $\mathrm{Fe}_{2} \mathrm{~N}$ phase at room temperature when the content of nitrogen increases from $25 \%$ to $33 \%$; $\mathrm{Fe}_{4} \mathrm{~N}$ phase, that contains around $20 \% \mathrm{~N}$, has distinct magnetic properties and FCC crystal structure and could be produced by controlled annealing of FeN phase; FeN phase has a low thermal stability because of the weak Fe-N bonding, etc. [11].

Open atmosphere cold plasma surface treatment (OACP-ST) is a relatively new process up-graded to the industrial stage for surface treatment, especially for polymers or textile material treatment [12-14]. OACP-ST is making its way towards implementation on metallic materials as well. It was reported that radiofrequency cold plasma treatment, performed in vacuum for $8 \mathrm{~h}$ on non-heated C38 carbon steel, resulted in the formation of a uniform structure of the sample surface, with an enrichment in nitrogen and a gradient of hardness versus depth [15].

AISI-304 steel, used in our work, is one of the most known and used materials in the manufacturing of the mechanical components in the automotive, chemical, textile, medical, airspace, etc. industries, due to its favorable mechanical, chemical, thermal and magnetic properties. It has the following chemical composition in $w \mathrm{t} \%: \max .0 .08 \%-\mathrm{C}$; max. $2 \%-\mathrm{Mn} ; \max 0.045 \%-\mathrm{P}$; max. $0.03 \%-\mathrm{S}$; max. $0.75 \%-\mathrm{Si} ; \max .0 .10 \%-\mathrm{N}_{2} ; 18-$ $20 \%-\mathrm{Cr} ; 8-12 \%-\mathrm{Ni}$ and $\mathrm{Fe}$ in balance [16]. However, the low hardness and deficient wear resistance of AISI 304 stainless steel (304SS) in certain environments limits its application in many fields. Several works report the improvement of their mechanical, tribological and protective properties by vacuum plasma ion nitriding.

R. Valencia et al. showed that the AISI 304 SS was successfully nitrided in vacuum $\left(10^{-1} \ldots 10^{-3} \mathrm{mbar}\right)$, by using plasma. The Vickers hardness has been increased several times compared to the untreated samples and the higher values were obtained at a higher pressure of the experimental pressure range, while the tribological properties improved substantially below $500{ }^{\circ} \mathrm{C}$ without it losing its corrosion resistance [17]. A short-term treatment and low temperature novel nitriding process that uses an "active screen" was reported to be more effective than the classic cathode glow-discharge process, leading to an increase in the surface hardness, in the diffusion depth of the nitride layers and in the 
abrasive wear resistance [18]. T. Balusamy and his collaborators sustain the capability of the Surface Mechanical Attrition Treatment (SMAT) to increase the depth of the nitrided layer formed on 304 SS [19]. Plasma nitriding was also used on welded joints of 304 SS parts, with good results in terms of surface hardness, phase formation and case depth [20]. AISI 316L subjected to the nitriding process at temperature lower than $450{ }^{\circ} \mathrm{C}$ presents a high nitrogen content expanded austenite phase that shows higher hardness and higher pitting corrosion resistance compared to the untreated material, the technological parameters of the nitriding process playing an important role in the hardness and $\mathrm{N}$ concentration [21]. Investigating the carbon behavior in low temperature plasma nitriding, $\mathrm{M}$. Tsujikawa et al. indicated an accumulated carbon layer beyond the nitrogen plateau, which means the low temperature plasma nitriding of austenitic stainless steels pushes carbon ahead of the nitride layer [22]. It has been found that the ion nitriding surface treatment improved the fatigue strength and increased the fatigue limit, depending on the case depth [23]. Furthermore, the thickness of the compound layer increased with an increase in the treatment time and temperature for the ion nitrided AISI 4340 steel [24].

To the extent of our knowledge, there are no scientific works reporting on the capability of the OACP-ST to improve the corrosion resistance, hardness or friction coefficient of metals or alloys in general (or of the 304 SS in particular) using only commercial nitrogen without any supplementary gas (e.g., nitrogen and hydrogen gas mixture that is used in classical or vacuum ion nitriding processes). However, some aspects of the OACP-ST influence on 304 SS were investigated $[25,26]$, where it was reported that plasma treatment in open atmosphere has a significant positive effect on the wettability and contact angle as well as on the surface free energy and surface roughness of the treated samples. The hydrophilicity of the treated surface was significantly improved by decreasing the surface contact angle and the treated surfaces exhibited lower carbon content than the untreated one $[25,26]$.

In this paper, we report the nitriding of 304 SS sample surface by open atmospheric cold plasma surface treatment, according to the Patent Application A00261/02.05.2017 of the authors A. O. Mateescu and G. Mateescu, registered at the Romanian State Office for Inventions and Trademarks (OSIM), aiming at the improvement of the corrosion resistance, mechanical and tribological behavior of the treated surfaces. AFM investigations for surface topography, corrosion resistance evaluation and mechanical and tribological results of treated and un-treated samples are presented below.

\section{Materials and Methods}

Three hundred and four SS sheets and commercial nitrogen (5.0) as a working gas (both process and cooling gas) at a pressure of 6 bar and a flow of $1.5 \mathrm{~m}^{3} / \mathrm{h}$ for cold plasma surface nitriding treatment were used. Plasma beam equipment with an open atmosphere cold plasma torch for surface treatment (Plasma Beam Equipment, Dienner Electronic $\mathrm{GmbH}$, Ebhausen, Germany) was employed. The main components of the cold plasma treatment in open atmosphere and the geometrical parameters of the plasma torch for the nitriding process are presented in Figure 1. The diameter of the plasma beam ranged from 10 to $12 \mathrm{~mm}$, while the height of the plasma beam could be selected from 5 to $10 \mathrm{~mm}$. For the $\mathrm{x}-\mathrm{y}$ movement of the plasma beam (PC controlled values), a CNC equipment type MINI-CNC engraving machine with a variable speed from 0.5 up to $20 \mathrm{~mm} / \mathrm{s}$ was used. The samples with dimensions of $20 \mathrm{~mm} \times 20 \mathrm{~mm} \times 2 \mathrm{~mm}$ were fixed on the CNC Machine and moved in $x$ direction with a speed selected in the range of $0.5 \mathrm{~mm} / \mathrm{s}$ up to $20 \mathrm{~mm} / \mathrm{s}$, at around $6 \mathrm{~mm}$ distance from the surface (on $\mathrm{z}$ axis), with repetition of movement on a new line in $x$ direction, at $4 \mathrm{~mm}$ distance on the $y$ axis. The general duration of the process was:

- $\quad$ a total time of the cold plasma treatment of $0.25 \mathrm{~h}$, with moving speed of plasma beam of $9 \mathrm{~mm} / \mathrm{s}$ for $3 \mathrm{~min} /$ line-cycle and 5 line-cycles/sample, for sample 1;

- a total time of the cold plasma treatment of $3 \mathrm{~h}$, with moving speed of plasma beam of $108 \mathrm{~mm} / \mathrm{s}$ for $36 \mathrm{~min} /$ line-cycle and 5 line-cycles/sample, for sample 2. 
An ultrasonic bath cleaning process of $0.5 \mathrm{~h}$ preceded the surface nitriding treatment of the AISI 304 SS samples.

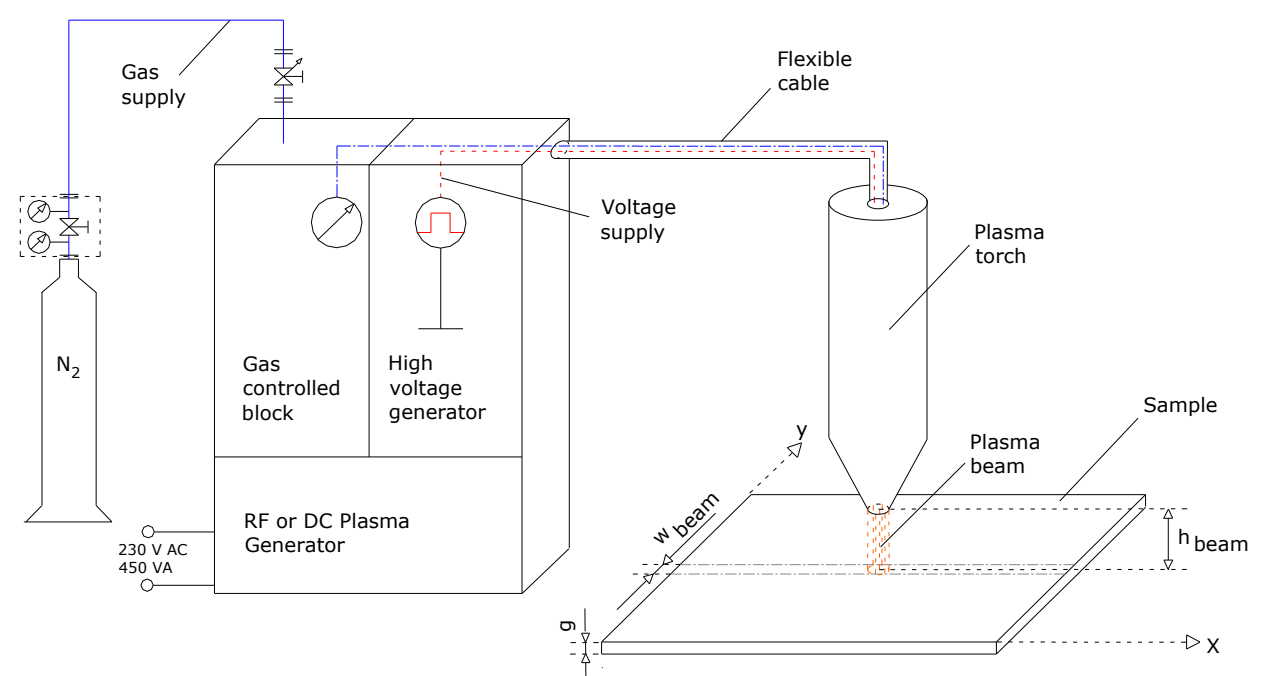

Figure 1. Plasma beam equipment for nitriding process of AISI 304 SS sample and geometrical parameters of the plasma beam.

AFM topography was performed with SPM-NTegra Prima AFM (NT-MDT, Russia) in semicontact mode, using a NSG 01 cantilever (resonance frequency: $83-230 \mathrm{kHz}$, elastic constant: $1.45-15.1 \mathrm{~N} / \mathrm{m}$, scan rate $1 \mathrm{~Hz}$, scan resolution of 512 samples per line). The AFM images were recorded on $10 \times 10 \mu \mathrm{m}^{2}$ scan surface. Grain size distributions, surface skewness and coefficient of kurtosis were calculated using NT-MDT Image Analysis 2 software.

Electrochemical measurements were conducted in a conventional three electrode cell: the working electrode (the sample), the corrosion electrode $(\mathrm{Pt})$ and the reference electrode (saturated calomel electrode-SCE) in $0.1 \mathrm{M}$ aqueous $\mathrm{NaCl}$ solution. All solutions were prepared from chemically pure (c.p.)/practical grade (p.a.) chemicals (Merck) and bi-distilled water. The corrosion tests are performed in the range $\pm 100 \mathrm{mV}$ vs. open circuit potential at a scan rate $1 \mathrm{mV} / \mathrm{s}$. The corrosion resistance (polarization resistance) and the corrosion potential are measured from Tafel plot. Measurements were performed using Voltalab PGstat model 301 (Radiometer Analytical, Lyon, France).

The instrumented indentation hardness and instrumented indentation elastic modulus of the untreated and treated 304 SS samples in OACP-ST were determined following the model of Oliver and Pharr [27]. Nanoindentation measurements (CSM Instruments (NHT2)-Berkovich diamond tip) were performed at different penetration depths in order to qualitatively assess the drop in hardness, caused by the limited nitrogen diffusion depth. As per the ISO 14577 standard (Metallic materials-Instrumented indentation test for hardness and materials parameters), at least 10 indentations were performed on each sample, with $30 \mathrm{~s}$ loading/unloading speeds up to the desired maximum indentation load and a $10 \mathrm{~s}$ pause between the loading and unloading stages, in order to minimize the creep effect. The friction coefficient of the samples was evaluated by ball-on-disk wear tests, using a Standard Tribometer, from CSM Instruments/Anton Paar (Peseux, Switzerland), in rotation mode. Six mm WC (tungsten carbide) balls were used as friction couples, with a normal applied load of $2 \mathrm{~N}$, a linear speed of $22 \mathrm{~cm} / \mathrm{s}, 3.5 \mathrm{~mm}$ and $4.5 \mathrm{~mm}$ radius tracks and a $600-\mathrm{m}$ stop condition. The samples were ultrasonically cleaned in isopropanol prior to the wear tests, in order to remove any impurities that might affect the wear test results. The variation of the friction coefficient as function of the test length was the main focus. 


\section{Results}

\subsection{AFM Analysis}

Figure 2 shows the AFM micrographs of the surface of bare stainless steel (Sample 0), sample 1 and sample 2 and Figure 3 presents the height histograms of AFM images. Images of all samples were processed and analyzed by means of the offline NT-MDT Image Analysis 2 software. As shown in A-C the films reveal a granular homogenous surface morphology. The following roughness parameters were determined for all samples: average roughness (the arithmetic average of absolute values of the surface height deviations measured from the mean plane), full width at half maximum-FWHM (determined from the Gauss fitting of the histograms), surface skewness and coefficient of kurtosis (see Table 1). The average roughness increases for treated samples of stainless steel up to $31.03 \mathrm{~nm}$. Grain boundaries become sharper and the matrix shows a less smooth appearance. These results could be explained by assuming that nitriding of stainless steel surface leads to the formation of more compact and higher aggregates.

Table 1. The roughness parameters of un-nitrided and nitrided AISI 304 SS.

\begin{tabular}{ccccc}
\hline Sample & $\begin{array}{c}\text { Average } \\
\text { Roughness } \\
\text { (nm) }\end{array}$ & $\begin{array}{c}\text { FWHM } \\
\mathbf{( n m )}\end{array}$ & $\begin{array}{c}\text { Surface } \\
\text { Skewness }\end{array}$ & $\begin{array}{c}\text { Coefficient of } \\
\text { Kurtosis }\end{array}$ \\
\hline $\begin{array}{c}\text { Sample 0 } \\
\text { (un-treated bare stainless steel) } \\
\text { Sample 1 }\end{array}$ & 4.14 & $11.61 \pm 0.04$ & 0.37 & 3.50 \\
$\begin{array}{c}\text { (0.25 h nitriding treatment) } \\
\text { Sample 2 } \\
\text { (3 h nitriding treatment) }\end{array}$ & 31.03 & $71.04 \pm 0.57$ & -0.30 & 1.32 \\
\hline
\end{tabular}

The analysis of the surface morphology in terms of average roughness, skewness and coefficient of kurtosis can be correlated with the experimental measurements of the friction coefficient. The skewness of the profile can be used to distinguish between profiles with similar roughness parameters, but different shape: a symmetrical height distribution has zero skewness and deep scratches give negative values, while high peaks result in positive values. In our case, sample 1 shows a negative surface skewness, indicating deep scratches and sample 2 a positive coefficient, but higher than the bare stainless steel. These results support the idea of grain boundary becoming sharper, with higher aggregates. On the other hand, the kurtosis coefficient describes the sharpness of the profile. The kurtosis coefficient of stainless steel is 3.50 (i.e., a leptokurtoic distribution), corresponding to many high peaks and low valleys. After nitriding the surface, the kurtosis coefficient decreases to 1.32 (sample 1) and 1.43 (sample 2), respectively, which describes a platykurtoic distribution corresponding to the few high peaks and low valleys.
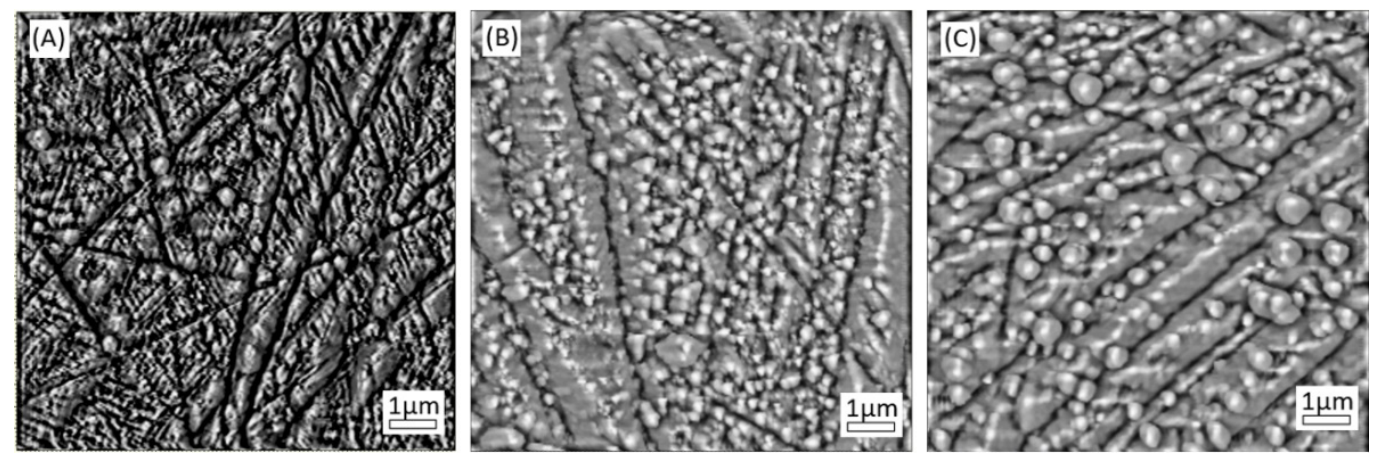

Figure 2. AFM micrograph of: Sample 0 (A), sample 1 (B) and sample 2 (C). Scan size $10 \mu \mathrm{m} \times 10 \mu \mathrm{m}$. 

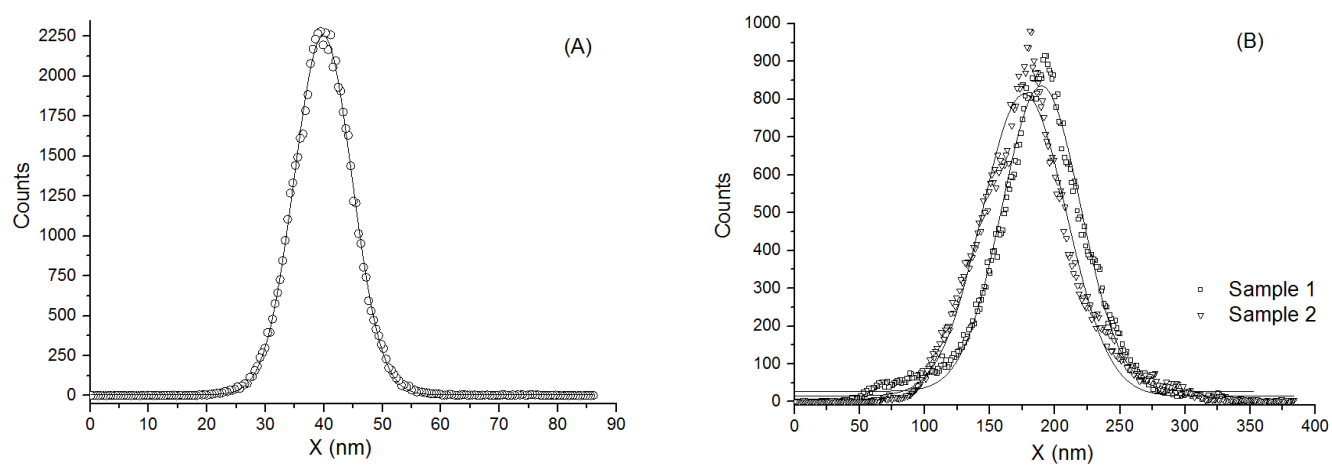

Figure 3. Height histograms of AFM images presented in Figure 2 of: Sample 0 (A), sample 1 and sample 2 (B).

\subsection{Corrosion Resistance Results}

The corrosion potential and the polarization resistance, determined from Tafel plot (see Figure 4), are summarized in Table 2, for bare stainless steel and samples 1 and 2. The stainless steels are usually quite cathodically relative to other alloys, as they exhibit electrode potentials, in saline water, from +500 to $-280 \mathrm{mV}$ vs. SCE [26]. The electrode potential ( $E_{\text {corr }}$ ) of bare stainless steel was found at $-117 \mathrm{mV}$ vs. SCE, with a polarization resistance $\left(R_{p}\right)$ of $94.84 \mathrm{k} \Omega / \mathrm{cm}^{2}$. Sample 1 has a corrosion potential more negative than stainless steel, $-211 \mathrm{mV}$ vs. SCE, but with a much higher $R_{p}$ of $177.47 \mathrm{k} \Omega / \mathrm{cm}^{2}$. On the other hand, sample 2 has the lowest corrosion potential, $-267 \mathrm{mV}$ vs. SCE, but with a lower $R_{p}$ of $76.37 \mathrm{k} \Omega / \mathrm{cm}^{2}$. Results of the Tafel extrapolation method show that the treated stainless steel has the lowest current density, which suggests that the nitriding process increases the corrosion resistance of bare stainless steel. The higher polarization resistance of sample 1 indicates that the nitrided stainless steel are more effective in protecting against corrosion. Moreover, the corrosion rate (calculated using Faraday's law, according to ASTM G-102) is significantly decreasing after the nitriding process, i.e., $0.30 \mu \mathrm{m}$ /year for sample 1 and $1.06 \mu \mathrm{m}$ /year for sample 2 compared to the $2.52 \mu \mathrm{m}$ /year for the bare stainless steel.

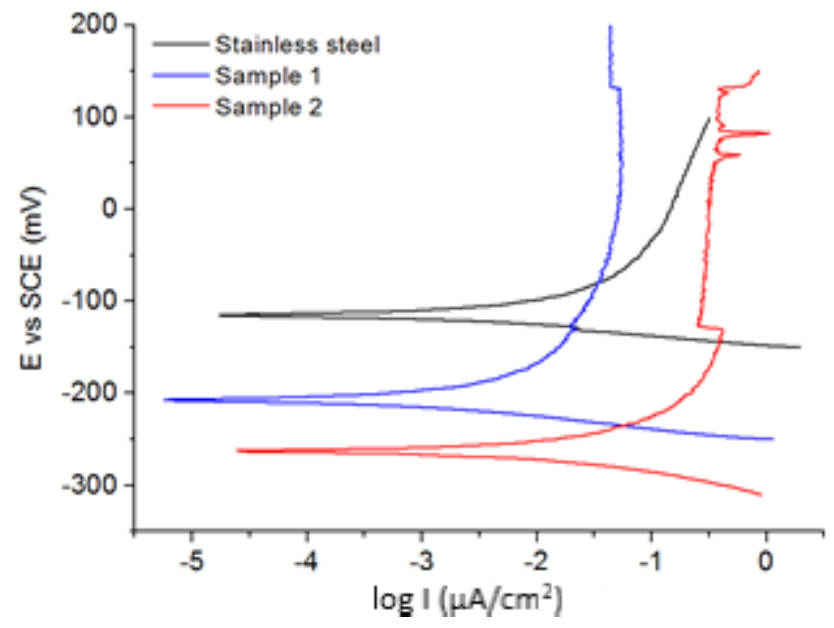

Figure 4. Polarization curve obtained in $0.1 \mathrm{M} \mathrm{NaCl}$ for bare stainless steel, sample 1 and sample 2. 
Table 2. Corrosion parameters for bare and nitriding stainless steel in $0.1 \mathrm{M} \mathrm{NaCl}$ determined by Tafel extrapolation method.

\begin{tabular}{|c|c|c|c|c|c|c|}
\hline Sample & $\begin{array}{c}E_{\text {corr }} \\
\left(m V_{S C E}\right)\end{array}$ & $\begin{array}{c}\mathrm{j}_{\text {corr }} \\
\left(\mu \mathrm{A} / \mathrm{cm}^{2}\right)\end{array}$ & $\begin{array}{c}\beta_{\mathrm{a}} \\
\left(\mathrm{mvdec}^{-1}\right)\end{array}$ & $\begin{array}{c}-\beta_{\mathrm{c}} \\
\left(\mathrm{mVdec}^{-1}\right)\end{array}$ & $\begin{array}{c}R_{p} \\
\left(k \Omega / \mathrm{cm}^{2}\right)\end{array}$ & $\begin{array}{c}C R \\
(\mu \mathrm{m} / \text { year })\end{array}$ \\
\hline $\begin{array}{c}\text { Sample 0 } \\
\text { (untreated bare } \\
\text { stainless steel) }\end{array}$ & -117 & 0.26 & 468.1 & 27.5 & 94.84 & 2.52 \\
\hline $\begin{array}{c}\text { Sample } 1 \\
\text { (0.25 h nitriding } \\
\text { treatment) }\end{array}$ & -211 & 0.03 & 40.3 & 26.0 & 177.47 & 0.30 \\
\hline $\begin{array}{c}\text { Sample } 2 \\
\text { (3 h nitriding } \\
\text { treatment) }\end{array}$ & -267 & 0.10 & 59.7 & 41.2 & 76.37 & 1.06 \\
\hline
\end{tabular}

\subsection{Mechanical Parameters: Hardness, Elastic Modulus and Wear Behaviour}

Table 3 contains the results obtained from the instrumented indentation analysis. The instrumented indentation hardness $\left(\mathrm{H}_{\mathrm{it}}\right)$ and elastic modulus $\left(\mathrm{E}_{\mathrm{it}}\right)$ were obtained for multiple penetration depths $\left(\mathrm{h}_{\mathrm{m}}\right)$ as a result of $1.5,2.5$ and $5 \mathrm{mN}$ loads $\left(\mathrm{F}_{\mathrm{m}}\right)$. One can notice that the highest hardness values are measured at low penetration depths as a direct result of the nitriding process. The variation of hardness as function of penetration depth can be observed in Figure 5. A steady decrease can be observed, towards hardness values associated to the untreated sample. A longer nitriding period results in slightly higher hardness values; however, the diffusion depth is relatively the same, regardless of nitriding duration.

Table 3. Surface mechanical characteristics as a result of nanoindentation analysis.

\begin{tabular}{|c|c|c|c|c|c|c|}
\hline $\begin{array}{c}\text { Sample-Load } \\
\text { No. }\end{array}$ & $\begin{array}{c}\mathrm{H}_{\mathrm{IT}}(\mathrm{O} \& \mathrm{P}) \\
\quad(\mathrm{GPa})\end{array}$ & $\begin{array}{c}\mathrm{E}_{\mathrm{IT}}(\mathrm{O} \& \mathrm{P}) \\
(\mathrm{GPa})\end{array}$ & $\mathrm{H} / \mathrm{E}$ & $\mathrm{H}^{3} / \mathrm{E}^{2}$ & $\begin{array}{c}h_{m}(O \& P) \\
(n m)\end{array}$ & $\begin{array}{c}F_{m} \\
(m N)\end{array}$ \\
\hline & Mean & Mean & & & Mean & \\
\hline $1-3$ & $5.81 \pm 0.63$ & $199.170 \pm 38.65$ & 0.028 & 0.0050 & $178.259 \pm 8.77$ & 5 \\
\hline $1-2$ & $5.78 \pm 1.44$ & $204.880 \pm 48.47$ & 0.026 & 0.0039 & $126.410 \pm 12.41$ & 2.5 \\
\hline $1-1$ & $6.81 \pm 1.08$ & $198.167 \pm 18.58$ & 0.034 & 0.0080 & $89.315 \pm 7.13$ & 1.5 \\
\hline $2-3$ & $5.41 \pm 0.76$ & $189.047 \pm 25.10$ & 0.028 & 0.0040 & $189.774 \pm 13.74$ & 5 \\
\hline $2-2$ & $6.18 \pm 1.30$ & $193.362 \pm 27.63$ & 0.031 & 0.0063 & $123.650 \pm 13.11$ & 2.5 \\
\hline $2-1$ & $7.04 \pm 1.38$ & $204.107 \pm 23.28$ & 0.034 & 0.0083 & $87.813 \pm 8.82$ & 1.5 \\
\hline
\end{tabular}

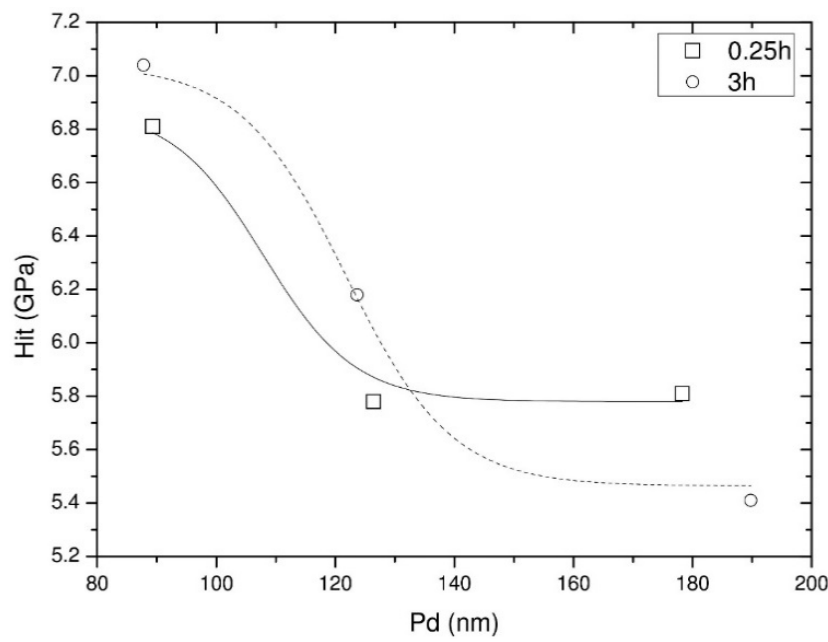

Figure 5. The variation in hardness as function of penetration depth.

The $\mathrm{H} / \mathrm{E}$ ratio can provide information about the wear resistance of the material in question [28], while the $\mathrm{H}^{3} / \mathrm{E}^{2}$ ratio gives information about the resistance to plastic deformation. 
Inferred from the H/E ratio, seen in Table 3, the nitride samples should exhibit relatively similar values for the dynamic friction coefficient, at least at the beginning of the test. This observation is confirmed by the graph shown in Figure 6. Even though the stop condition for the wear tests was set at $600 \mathrm{~m}$, the graph from Figure 6 shows only the region up to $20 \mathrm{~m}$, to better visualize the differences in the earlier stages of the friction tests. Past this value $(20 \mathrm{~m})$, the friction coefficient was stable throughout the entire tests. A low friction regime is noticed for the nitrided samples; however, the distance of this regime is significantly lower for the $0.25 \mathrm{~h}$ treated sample. Both the slightly lower hardness and the smaller diffusion depth are responsible for this behavior, due to the fact that the nitrided material is removed easier from the surface of the sample. Once the nitrided material is removed from the $3 \mathrm{~h}$-treated sample, the dynamic friction coefficient values are relatively close to the ones exhibited by the untreated sample. There is a clear correlation between the nitriding period and the wear resistance of the surface, for longer processing stages, one should expect a better wear behavior.

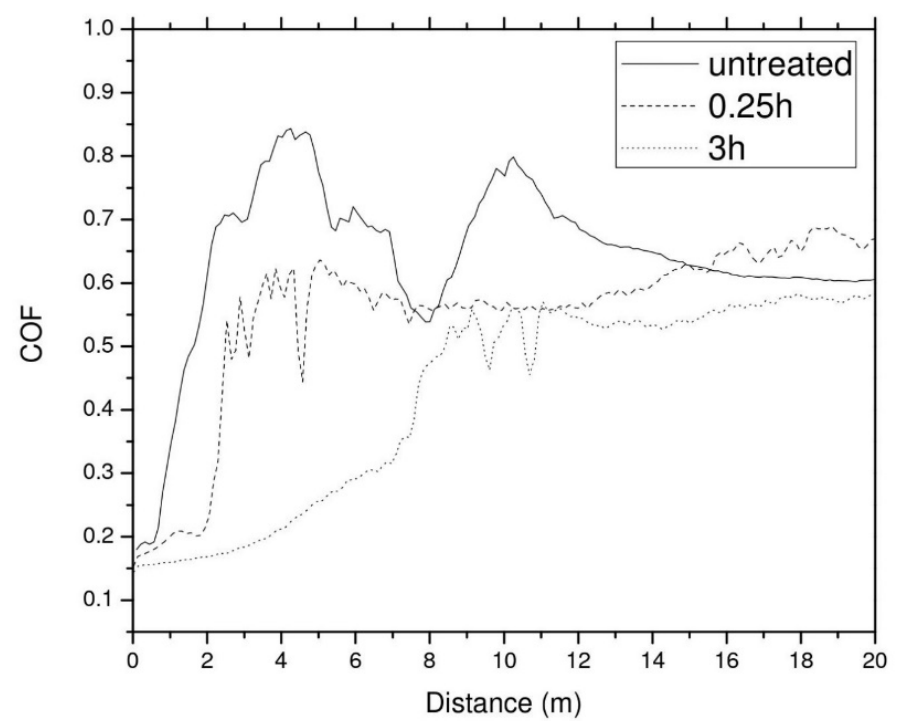

Figure 6. Dynamic friction coefficient variation, as a function of sliding distance.

\section{Conclusions}

Surface nitriding treatment by cold plasma in open atmosphere at low temperature was performed on AISI 304 SS samples.

Surface morphology analyzed by AFM shows that the open atmosphere with cold plasma treatment determines an increase of the roughness from around $4 \mathrm{~nm}$ (for untreated stainless steel—sample 0) to around 30-31 nm (samples 1 and 2).

The corrosion resistance has improved for the nitrided samples as the corrosion potential has decreased from $-117 \mathrm{mV}$ for untreated bare stainless steel (sample 0 ) down to $-211 \mathrm{mV}$ for $0.25 \mathrm{~h}$ treatment in cold plasma (sample 1) and $-211 \mathrm{mV}$ for $3 \mathrm{~h}$ treatment (sample 2).

Diffusion of the nitrogen in the sample depth with nitriding process of 304 SS samples, by open atmosphere cold plasma surface treatment method with commercial nitrogen (5.0), is put in evidence in addition to the indentation test when the highest hardness values were measured at the lowest penetration depth and the lowest hardness value was measured at the highest penetration depth.

The coefficient of friction with very low values (less than 0.20) was obtained for the treated samples, but these low values were observed only for a relatively short sliding length (lower than $4 \mathrm{~m}$ ), that increased with longer treatment process.

Improvement of surface quality (hardness, coefficient of friction, corrosion resistance) of the AISI 304SS samples by cold plasma treatment is strongly influenced by the treatment duration and technical parameters of the plasma jet (intensity, diameter and length of 
plasma jet). The temperature increasing of the metallic treated surfaces by cold plasma is also very reduced for long time treatments, without using external heating sources of the metallic samples. The low cost of the equipment for open atmosphere cold plasma treatment compared to that for vacuum ion nitriding is another reason for using this new surface treatment for different practical applications (e.g., the enhanced surface characteristics of large dimension industrial tools.)

Author Contributions: Conceptualization, A.O.M. and G.M., Methodology, C.C.; Validation, G.M. and C.S.; Formal analysis, I.S. and D.U.; Investigation, A.B. and D.C.; Resources, A.B. and C.C.; Writing—original draft preparation, A.O.M.; Writing—review \& editing, G.M. and C.S.; Visualization, A.O.M. and D.C.; Supervision, G.M., I.S. and C.S.; Project administration, G.M. All authors have read and agreed to the published version of the manuscript.

Funding: This research received no external funding.

Institutional Review Board Statement: Not applicable.

Informed Consent Statement: Not applicable.

Acknowledgments: The authors acknowledge for the financial support from Nucleu Program 1906 01 03. We hereby acknowledge the structural founds project PRO-DD (POS-CCE, O.2.2.1., ID 123, SMIS 2637, ctr. No 11/2009) and founds from ROSA STAR project ctr. 68/2013 for providing the infrastructure used in this work.

Conflicts of Interest: The authors declare no conflict of interest.

\section{References}

1. Mateescu, A.O.; Mateescu, G. Procedure for Improvement of Mechanical, Tribological and Protective Qualities of Some Metallic Alloys by Their Surface Treatment in Open Atmosphere with a Cold Plasma Jet of Certain Gases that Ensure Their Superficial Nitriding or Carbonitriding. Romanian State Office for Inventions and. Trademarks Patent Application A00261, 2 May 2017.

2. Miteemeijer, E.J. Fundamentals of Nitriding and Nitrocarburizing. In ASM Handbook, Steel Heat Treating Fundamentals and Processes; ASM International: Almere, The Netherlands, 2013; Volume 4A, pp. 619-646.

3. Elwart, J.; Hunger, R. Plasma (Ion) Nitriding and Nitrocarburizing of Steels. In ASM Handbook, Steel Heat Treating Fundamentals and Processes; ASM International: Almere, The Netherlands, 2013; Volume 4A, pp. 690-703.

4. Plasma Nitriding History and Processes, Northiest Coating Technologies. Available online: http:/ / www.northeastcoating.com/ products / plasma-nitriding/process (accessed on 31 March 2017).

5. Plasma Nitriding Process, TPP Information Centre. Available online: http://www.tppinfo.com/heat_treatment/plasma_ nitriding_coating/plasma_nitriding.htm (accessed on 31 March 2017).

6. Wang, L. Surface modification of AIS 304 austenitic stainless steel by plasma nitriding. Appl. Surf. Sci. 2003, $211,308-314$. [CrossRef]

7. Pye, D. Practical Nitriding and Ferritic Nitrocarburizing; ASM International: Novelty, OH, USA, 2003; ISBN 978-0-87170-791-8.

8. Thermodinamics of Chemical Equilibrium. Available online: http://www.chem1.com/acad/webtext/thermeq/ (accessed on 3 April 2017).

9. Howard, S.M. Ellingham Diagram for Selected Nitrides. Available online: http://showard.sdsmt.edu/MET320/Handouts/ EllinghamDiagrams/Ellingham_v22_Macro.pdf (accessed on 4 April 2017).

10. Göhring, H.; Fabrichnaya, O.; Leineweber, A.; Mittemeijer, E.J. Thermodynamics of the Fe-N and Fe-N-C systems: The Fe-N and Fe-N-C phase diagrams revisited. Metall. Mater. Trans. A 2016, 47A, 6173-6186. [CrossRef]

11. Khan, W.; Wang, Q.; Jin, X.; Feng, T. The effect of sputtering parameters and dopping of copper on surface free energy nd magnetic properties of iron and iron nitride nano thin films on polymer substrate. Materials 2017, 10, 217. [CrossRef]

12. Dienner Elektronic GmbH, Atmospheric Pressure Plasma. Available online: https://www.plasma.com/en/plasmatechnik/ atmospheric-pressure-plasma/ (accessed on 4 April 2017).

13. Plasmatreat GmbH, Open Air Plasma Technology. Available online: https://www.plasmatreat.com/plasma-technology/openairatmospheric-plasma-technique.html (accessed on 4 April 2017).

14. Enercon Industry, Plasma Treatment Industry Applications. Available online: http://www.enerconind.com/treating/library/ technology-spotlights / plasma-treatment-industry-applications.aspx (accessed on 4 April 2017).

15. Bouanis, F.Z.; Bentiss, F.; Bellayer, S.; Vogt, J.B.; Jama, C. Radiofrequency cold plasma nitrided carbon steel: Microstructural and micromechanical characterization. Mater. Chem. Phys. 2011, 127, 329-334. [CrossRef]

16. AK Steel, 304/304L Stainless Steel Data Sheet. Available online: http://www.aksteel.com/pdf/markets_products/stainless/ austenitic/304_304L_Data_Sheet.pdf (accessed on 4 April 2017).

17. Valencia, R.; Lopez-Callejas, R.R.; Munoz-Castro, A.; Barocio, S.R.; Chavez-Alarcon, E.; Godoy-Cabrera, O. Nitriding of AISI 304 stainless steel by PIII in DC and RF toroidal discharges. Braz. J. Phys. 2004, 34, 1594-1597. [CrossRef] 
18. Ogorek, M.; Skuza, Z.; Fraczek, T. The effiecncy of ion nitriding of austenitic stainless steel304 using the "active screen". Metalurgija 2015, 54, 147-150.

19. Balusamy, T.; Sankara-Naraynan, T.N.; Ravichandran, K.; Park, I.S.; Lee, M.H. Plasma nitriding of AISI 304 stainless steel: Role of surfacemechanical attritiontreatment. Mater. Charact. 2013, 85, 38-47. [CrossRef]

20. Alphonsa, J.; Padsala, B.A.; Chauhan, B.J.; Jhala, G.; Rayjada, P.A.; Chauhan, N.; Soman, S.N.; Raole, P.M. Plasma nitriding on welded joints of AISI 304 stainless steel. Surf. Coat. Technol. 2013, 228, 5306-5311. [CrossRef]

21. Olzon-Dionysio, M.; Campos, M.; Higa, O.Z.; da Cunha, T.F.; de Souza, S.D. Investigating the correlation between some of the properties of plasma nitrided AISI 316L stainless steel. Mater. Res. 2013, 16, 1052-1057. [CrossRef]

22. Tsujikawa, M.; Yamauchi, N.; Ueda, N.; Sone, T.; Hyrose, Y. Behaviour of carbon in low temperature plasma nitriding layer of austenistic stsinless steel. Surf. Coat. Technol. 2005, 193, 309-313. [CrossRef]

23. Sirin, S.Y.; Sirin, K.; Kaluc, E. Effect of the ion nitriding surface hardening process on fatigue behaviour of AISI 4340 steel. Mater. Charact. 2008, 59, 351-358. [CrossRef]

24. Sirin, S.Y.; Kaluc, E. Improvement of surface properties of low carbon steel by nitriding treatment. Mater. Des. 2012, 36, 741-747. [CrossRef]

25. Tang, S.; Kwon, O.J.; Lu, N.; Choi, H.S. Surface characterization of AISI 304L stainless steel after an atmospheric pressure plasmatreatment. Surf. Coat. Technol. 2005, 195, 298-306. [CrossRef]

26. Lin, J.W.; Chang, H.C. Surface modification of SUS304 stainless steel by atmospheric pressure Ar/ $\mathrm{N}_{2} / \mathrm{O}_{2}$ plasma. Nucl. Instrum. Methods Phys. Res. B 2011, 269, 1801-1808. [CrossRef]

27. Oliver, W.C.; Pharr, G.M. An improved technique for determining hardness and elastic modulus using load and displacement sensing indentation experiments. J. Mater. Res. 1992, 47, 1564-1583. [CrossRef]

28. Oberle, T.L. Properties influencing Wear of Metal. J. Met. 1951, 3, 438. 